\title{
2D-Raman Correlation Spectroscopy as a Method to ReCognize OF the INTERACTION AT THE INTERFACE OF CARBON LAYER AND ALBUMIN
}

Submitted: 13 ${ }^{\text {th }}$ June 2019; accepted 10 ${ }^{\text {th }}$ September 2019

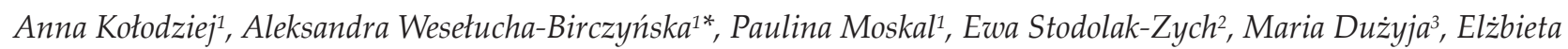
Długoń2, Julia Sacharz1, Marta Błażewicz²

DOI: 10.14313/ JAMRIS/3-2019/30

\begin{abstract}
:
In modern nanomaterial production, including those for medical purposes, carbon based materials are important, due to their inert nature and interesting properties. The essential attribute for biomaterials is their biocompatibility, which indicates way of interactions with host cells and body fluids. The aim of our work was to analyze two types of model carbon layers differing primarily in topography, and developing their interactions with blood plasma proteins. The first layer was formed of pyrolytic carbon C (CVD) and the second was constructed of multi-walled carbon nanotubes obtained by electrophoretic deposition (EPD), both set on a Ti support. The performed complex studies of carbon layers demonstrate significant dissimilarities regarding their interaction with chosen blood proteins, and points to the differences related to the origin of a protein: whether it is animal or human. However the basic examinations, such as: wettability test and nano sctatch tests were not sufficient to explain the material properties. In contrast, Raman microspectroscopy thoroughly decodes the phenomena occurring at the carbon structures in contact with the selected blood proteins. The $2 D$ correlation method selects the most intense interaction and points out the different mechanism of interactions of proteins with the nanocarbon surfaces and differentiation due to the nature of the protein and its source: animal or human. The $2 D$ correlation of the Raman spectra of the MWCNT layer+HSA interphase proves an increase in albumin B-conformation. The presented results explain the unique properties of the $C$ layers (CVD) in contact with human albumin.
\end{abstract}

Keywords: Multi-Walled Carbon Nanotubes; Pyrolytic Carbon; Carbon Layers; Raman Microspectroscopy; Plasma Blood Proteins, 2D Correlation.

\section{Introduction}

The diverse and growing needs of modern societies can be met by the extraordinary development of nanotechnology methods that represent a unique position for varies application areas and importance for economic reasons [1]. The presented research topic concerns materials for regenerative medicine due to their specificity included in the area of nanomedicine. Size of nano-additives may lead to their direct involvement in the processes and even biological structures [1-7]. Innovative biomaterials have contributed to the field of controlled drug delivery applications [8-10], cardiovascular diseases [11-13] and orthopedics [3,14], while novel materials with carbon nanotubes coatings are desirable for application as sensors and neural electrodes or as a platform for Central Nervous System diseases [15-17]. Selecting appropriate nanofiller can cause that structural, mechanical and electronic properties of nanocomposite material are shaped in a manner that would induce the desired characteristics of interaction with the biological environment [18]. So the nanoparticle by modern nanotechnology methods may be adjusted to modify, as intended, the polymer matrix [19-21], or to alter the surface of the synthetic material that comes into contact with the tissue of the living organism [11, 22-26].

Carbon materials are attractive due to their unique properties and large variety of carbon structures and nanostructures, so they can be used as a modifying particles [27]. Two types of carbon structures, pyrolytic carbon and multiwall carbon nanotubes (MWCNTs), have been chosen to identify their properties. Pyrolytic carbon can occur with different microstructures, that depend on the various forming conditions, belongs to a group of turbostratic carbons, with a structure related to graphite. However, graphite consists of carbon atoms that are covalently bonded in hexagonal arrays. These arrays are stacked and held together by weak interlayer binding, while pyrolytic carbon and other turbostratic carbons present a lack of order in the neighboring graphitic layers, so that occur wrinkles or distortions within layers. This ensures that the pyrolytic carbon has an improved durability compared to graphite [28]. Although this type of structure has been the most popular material available for artificial mechanical heart valves for about half a century there are some requirements to consider. The second type of the analyzed forms of carbon are MWCNTs, that are fibrous nanostructures [29], recently used are synthesized $[27,29]$. They can be also found naturally or as a byproduct of industrial processes $[30,31]$. The Ijima discovery caused a great interest for CNTs because of their characteristics: small size and mass, high strength, and high electrical conductivity [32]. 
For biomaterials the most important feature is their biofunctionality and biocompatibility, which refers to mechanical characteristic and to the interaction with host cells and fluids, respectively [33]. The biological response to the synthetic material is determined at the interface of the surface of a biomaterial and cell. One must be aware that the interface is complex, as biomolecules and synthetic material are composed of three-dimensional entities [34]. Therefore, the number of surface parameters determining the interfacial area such as: surface morphology, roughness (micro and nano), wettability, and the degree of crystallinity are parameters that result from the surface properties and significantly affect the biological properties of the material $[25,26$, 35-37].

Research on the adsorption of protein to synthetic material is considered as method to assess biomaterials quality, not only that in blood-contacting applications. It is considered that the adsorption of selected proteins, may reveal the specific biological properties of the examined nanomaterials. Usually albumin is selected to study its interaction with the surface of the nanomaterial. Albumin is the blood plasma protein of the next highest abundance after hemoglobin, which is involved in transport and storage and regarded as an inhibitor of blood clotting [38].

The commonly used are proteins of animal origin, which are considered to be equivalents of human protein. However, our earlier studies have shown that animal equivalents differently affect the surface of a carbon material than human proteins $[25,26]$. Therefore, modeling interactions with proteins of animal origin can be questioned in some cases. As target proteins, albumin from chicken egg white (Alb), bovine serum albumin (BSA) and human serum albumin (HSA), were employed to check their influence on the surface during performed research.

Conventional methods of material engineering such as wetting angle measurement and electron microscopic techniques (SEM) were employed to obtain the characteristics of the materials surface. The mechanical properties of the protein layers on the materials were tested with the Nano Scratch Tester. This method was applied to study the adhesion and scratch resistance of model coatings incubated with selected proteins. Then, materials were tested using Raman spectroscopy. The Raman spectroscopy was selected as an important spectroscopic technique to test short-range ordering. It has been used to describe the structure of two reference carbon layers and then the effect of adsorption on these layers of selected plasma proteins. Finally, a 2D Raman correlation spectroscopy was applied to the collected Raman spectra and allowed for the resolution of the phenomena occurring at the interphase, the carbon layer surface in contact with albumin, the most abundant blood proteins. In this mathematical analysis as an external perturbation the spatial position, in which the spectrum was measured, was taken into account.

\section{Materials and Methods}

\subsection{Preparation of Carbon Layers on Titanium}

Titanium plates (Grade 2 according to ASTM B265) in the form of discs with a diameter of $12 \mathrm{~mm}$ and a thickness of $0.5 \mathrm{~mm}$ were chosen as appropriate substrates for the deposition of carbon layers, which were: pyrolytic carbon (C (CVD)) and carbon nanotubes (MWCNTs) layer.

The first, pyrolytic C-layer was obtained in the Plasma-enhanced chemical vapor deposition process (PECVD; Elettrorava, Italy). All depositions were performed by the RF PECVD method, in which the plasma was generated by radio frequency waves of 13.56 $\mathrm{MHz}$ and of power $60 \mathrm{~W}$. The formation of the layers was preceded by ion-etching in argon plasma during 10 minutes to eliminate of the TiOx surface layer. Then the C-layer layer was deposited at room temperature $\left(25^{\circ} \mathrm{C}\right)$ during 30 minutes from a methane (gas flow $10 \mathrm{~cm}^{3} / \mathrm{min}$ ) and argon (gas flow $75 \mathrm{~cm}^{3} / \mathrm{min}$ ) mixture, while the chamber pressure was kept constant (53 Pa). Argon was used as inert gas.

The second layer of MWCNTs (\#1213NMGS, Nanostructured \& Amorphous Materials, Inc., USA; outside diameter 10-30nm; core diameter 5-10nm, length of 1-2 $\mu \mathrm{m}$ and purity $>95 \%$.) was produced in the electrophoretic deposition (EPD). Details on the oxidizing procedure, preparation of the suspension, titanium handling and EPD set-up are presented in our previous studies $[24,25,26]$.

The albumin from chicken egg white (Alb), bovine serum albumin (BSA), and human serum albumin (HSA), were purchased from Sigma-Aldrich (Poland). Both carbon coatings were incubated in 1\% albumin solution for 15 minutes.

\subsection{SEM Images Analysis}

The morphology and chemical composition of the obtained coatings were examined using a scanning electron microscope Nova Nanosem (FEI) equipped with an adapter for EDS X-ray microanalysis (EDAX). The system was operated with $10-15 \mathrm{kV}$ accelerating voltage, high vacuum mode.

\subsection{Wettability Measurements}

The contact angle [ $\theta$ ] for a liquid droplet on a tested, solid surface, was specified between the surface of the liquid and the outline of the contact surface, in the point where three phases meet: solid, liquid and gas. The contact angle measurements were taken using a direct method (DSA 10 Kruss goniometer). The tests were performed at room temperature applying the sitting drop technique (the drop of deionized water of $0.15-0.25 \mu \mathrm{l}$ in volume). The measurements were taken five times in order to found variability and the standard deviation (SD) (that was estimated as \pm $2.5 \%$ ). All experiments were performed for reference and both tested surfaces and also for the selected blood proteins conditioned with tested surfaces. All tests were performed under ambient conditions. 


\subsection{The Nano Scratch Test}

All tests were carried on a platform with the NST (Nano Scratch Tester) head made by CSM Instruments SA (currently Anton Paar TriTec) (Switzerland). The parameters, while testing, were set as follows: the load $F_{n}$ increased linearly from 0,1 to $5 \mathrm{mN}$ on the $3 \mathrm{~mm}$ distance, the speed of loading was set for $10 \mathrm{~mm} / \mathrm{min}$ and the Rockwell certified indenter radius was equal to $2 \mu \mathrm{m}$.

Two nanocomposite layers were analyzed: the C-layer grown in the CVD process and the MWCNTs deposited in the Ti support, after incubation with chicken egg white albumin and human serum albu$\min (\mathrm{HSA})$.

\subsection{Raman microspectroscopy}

A Renishaw inVia spectrometer, connected to a Leica microscope, was used for the measurements of the Raman spectra. The beam from a $514.5 \mathrm{~nm} \mathrm{Ar}^{+}$ ion Modu Laser was focused on the samples by 100x magnifying, a high numerical aperture $(\mathrm{NA}=0.9)$ topclass Leica objective for standard applications. Laser power was kept sufficient low, c.a. 1-3 mW at the sample, to ensure minimum disturbances to the samples.

\subsection{D Raman Correlation}

The generalized 2D correlation analysis based on the Noda method [39-41] was performed using Raman spectra as an input data for generating the correlation maps. The spatial position was regarded as an external perturbation [42]. The five points, morphologically similar were measured for each sample, and they were regarded as a dynamical spectra in the $2 \mathrm{D}$ correlation. 2Dshige, v.1.3 software was employed [43].

\section{Results and Discussion}

\subsection{SEM Images of Carbon Layers}

SEM investigations indicate dissimilarities in the topography of both materials. Two types of carbon structures are different primarily in the topography. The first coating was a layer formed of pyrolytic carbon (CVD) (Fig.1A) and the second was constructed of multi-walled carbon nanotubes obtained by electrophoretic deposition (EPD) (Fig. 1B), both set on a Ti support. A slight, intentional difference in the magnification of both images allows to see the specificity of the structure of micro- and nano-layer of C (CVD) and MWCNTs, respectively.

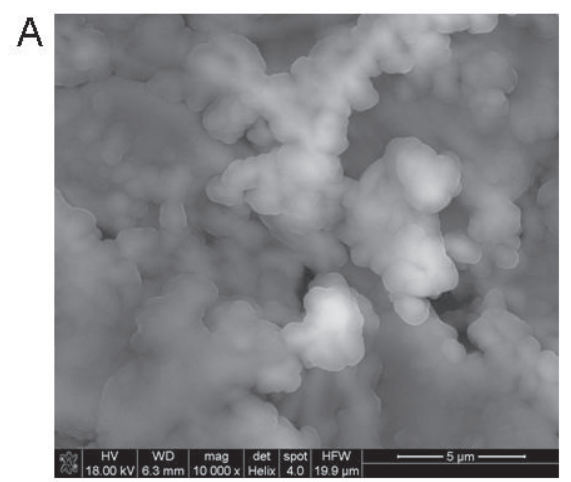

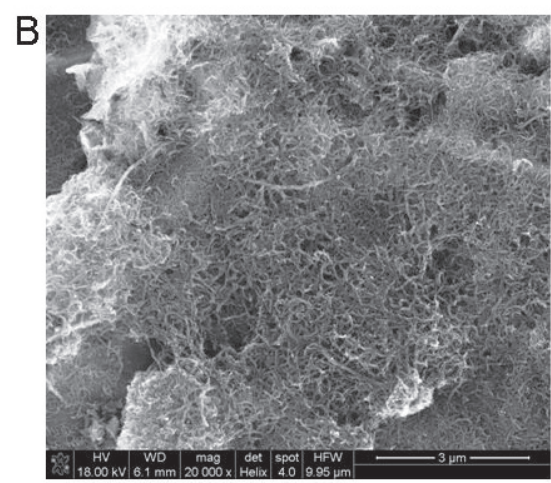

Fig. 1. SEM image of: (A) C (CVD) layer 10000x magnification, (B) MWCNTs (EPD) layer 20000x magnification.

\subsection{Wettability of Carbon Layers}

The surfaces wettability was analyzed by the static sessile drop method. The contact angles of water droplets on the top face of the reference C (CVD) layer are $82.2 \pm 2.8^{\circ}$, respectively (Figure $2 \mathrm{~A}$ ). The $\mathrm{C}$ (CVD) layer does not change the specificity of the surface with respect to the titanium substrate [26]. The difference in the contact angles for C (CVD) incubated with Alb $\left(78.4 \pm 2.3^{\circ}\right)$ and HSA $\left(84.5 \pm 1.9^{\circ}\right)$ with comparison to a reference the C (CVD) layer is not so significant, it fits within the limit of 5\% (Figure 2A). However, the C (CVD) incubation in BSA leads to the creation of a film with hydrophobic characteristics and contact angle of $112.0 \pm 6.7^{\circ}$.

The contact angles on the top face of the MWCNTs nanocomposite layer is $25.0 \pm 0.9^{\circ}$ (Figure $2 \mathrm{~B}$ ). This value implies a hydrophilic character of the surface of the MWCNTs coating. The Alb and HSA form a layer having a wettability $62.6 \pm 1.3^{\circ}$ and $57.3 \pm 0.3^{\circ}$, respectively. The BSA conditioned MWCNTs nanocarbon layer reaches the highest contact angle of $77.1 \pm 1.3^{\circ}$.
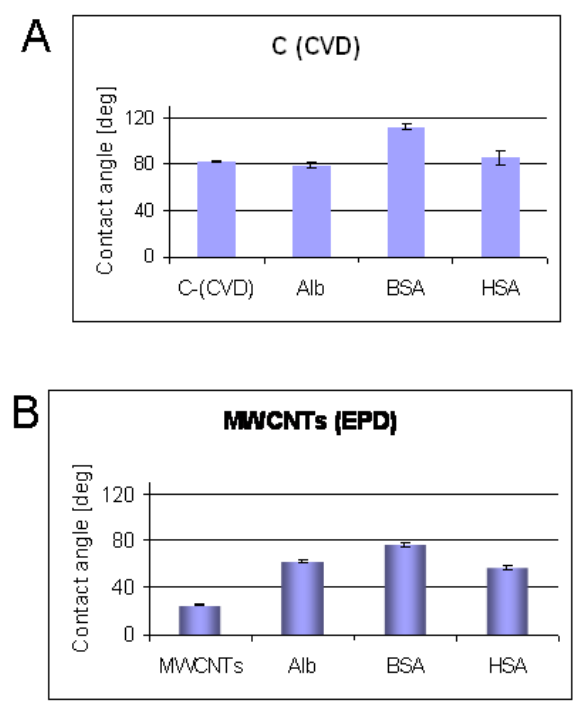

Fig. 2. Wettability of studied reference carbon samples (A) C (CVD) layer; (B) MWCNTs (EPD) layer, and after incubation with selected proteins. 


\subsection{Nano Scratch Test}

The performed test consisted of three steps. In the first step the profile of the sample (Pre Scan) was collected. In the second phase the indenter was pressed into the sample with linearly increasing load and moving along the sample at a defined length to scratch off the coating (test phase). During the third step the profile inside scratch (Post Scan) was accumulated. After the performed scratch the panoramic photograph is taken and the obtained features are analyzed.

HSA has the best adhesion to the C (CVD) layer (Table 1). This coating did not break during the performed test and the Ti substrate is not visible. It can be observed that the C (CVD) layer with a thin HSA sheet looks like a "pressed and smeared" during the test and therefore presents the best adhesion to the Ti base. In addition, violation of coating, chipping or cracking up to the $5 \mathrm{mN}$ load is not observed.

Tab. 1. Summary of the Scratch test Parameters (linear scrach; load range 0.1-5 $\mathrm{mN}$; loading rate $10 \mathrm{mN} / \mathrm{min}$ ).

\begin{tabular}{|c|c|}
\hline Sample & critical load $[\mathrm{mN}]$ \\
\hline $\mathrm{C}(\mathrm{CVD})+\mathrm{Alb}$ & coating failed at $2.16 \pm 0.20$ \\
\hline $\mathrm{C}(\mathrm{CVD})+\mathrm{HSA}$ & coating is not destroyed \\
\hline MWCNTs + Alb & coating failed at $1.63 \pm 0.10$ \\
\hline MWCNTs + HSA & coating failed at $2.17 \pm 0.16$ \\
\hline
\end{tabular}

For the MWCNTs nanolayer the HSA film is de-laminated with a load of about $2-2.5 \mathrm{mN}$. It is observed that the entire carbon nanolayer along with the thin film of protein is detached from the Ti substrate.

Adhesion of the Alb to the carbon C (CVD) layer is better, but the difference is small, the surface is scratched with a load of about $2.16 \mathrm{mN}$. The surface of the Alb on the MWCNTs nanolayer is scratched off easily, the visible surface of the Ti substrate is noticeable from the start of the test which means that the critical load for this layer is below $1.63 \mathrm{mN}$.

\subsection{Raman Microspectroscopy Characterization of Carbon Layers and their Interaction with Selected Blood Proteins}

The Raman band positions and assignments of the reference carbon layers excited by the $514.5 \mathrm{~nm}$ laser line are collected in Table 2. The first, the C (CVD) layer is formed of pyrolytic carbon, which is an anisotropic material. Therefore, only the main G- and D-bands are observed, what proves the graphite-type arrangement in this coating (Figure 3A). For the second, MWCNTs nano-layer, in addition to G- and D- also characteristic $2 \mathrm{D}, \mathrm{D}^{\prime}$ and $\mathrm{D}+\mathrm{D}^{\prime}$ bands are visible confirming more complex organization in this coating (Figure 3B) .
Tab. 2. Observed Raman bands $\left[\mathrm{cm}^{-1}\right]$ and their assignments for carbon coatings excited with $514.5 \mathrm{~nm}$ laser line.

\begin{tabular}{|c|c|c|}
\hline Sample & $\begin{array}{c}\text { Peak } \\
\text { position } \\
{\left[\mathrm{cm}^{-1}\right]}\end{array}$ & Assignment [20-28, 44-47] \\
\hline $\mathrm{C}(\mathrm{CVD})$ & 1349 & \multirow{2}{*}{$\begin{array}{l}\text { D-mode; breathing mode that } \\
\text { requires a defect for its activation }\end{array}$} \\
\hline $\begin{array}{l}\text { MWCNTs/ } \\
\text { (EPD) }\end{array}$ & 1364 & \\
\hline $\mathrm{C}(\mathrm{CVD})$ & 1594 & \multirow{2}{*}{$\begin{array}{l}\text { G-mode; } \mathrm{E}_{2 \mathrm{~g}} \text { mode at the Brillouir } \\
\text { zone center }\end{array}$} \\
\hline MWCNTs (EPD) & 1595 & \\
\hline MWCNTs (EPD) & 1633 & $\begin{array}{l}\text { D'-mode; effect of double } \\
\text { resonance as an intravalley } \\
\text { process } \\
\end{array}$ \\
\hline MWCNTs (EPD) & 2713 & $\begin{array}{l}\text { 2D (G'); second order of the } D \\
\text { peak }\end{array}$ \\
\hline MWCNTs (EPD) & 2956 & $\begin{array}{c}\mathrm{D}+\mathrm{D}^{\prime} \text {; combination of phonons } \\
\text { with different momenta, requires } \\
\text { a defect for theirs activation }\end{array}$ \\
\hline
\end{tabular}

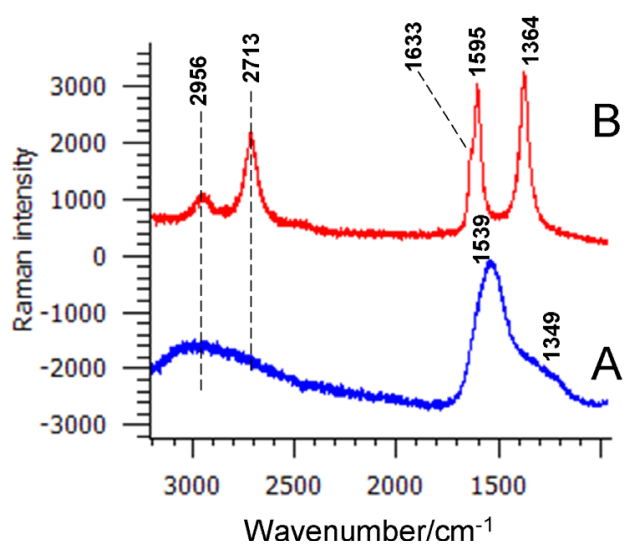

Fig. 3. Raman spectra for reference carbon layers (A) C (CVD), and (B) MWCNTs (EPD); $514.5 \mathrm{~nm}$ excitation line.

The G-band at ca. $1580 \mathrm{~cm}^{-1}$ is typical for the $\mathrm{sp}^{2}$ carbon materials and is assigned to the high frequency $E_{2 g}$ optical phonon [44]. The G-band position for the C (CVD) differs from that for the MWCNTs (EPD) layer, which is more heterogenous $[45,46]$.

Due to the excellent sensing properties of the carbon particle, the interaction with proteins can be observed and determined. The interaction occurs in the interphase region, between the two phases, and depends on both of them, on the type of carbon material and on protein (Fig. 4). The noticed shift of the G-band position shows the identifiable type of interaction in relation, first of all, to the reference coating. Furthermore, the positions of the G-band for the animal albumins, Alb and BSA, differ from that of HSA, what confirms that interaction occurs between the thin protein layer and the carbon coating as well as their specificity for different types of albumin.

Therefore, you need to consider what properties of the carbon layers are crucial in the application you are working on. 
A

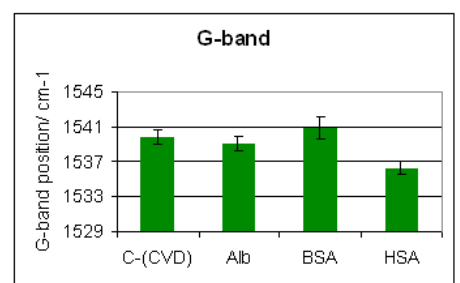

B

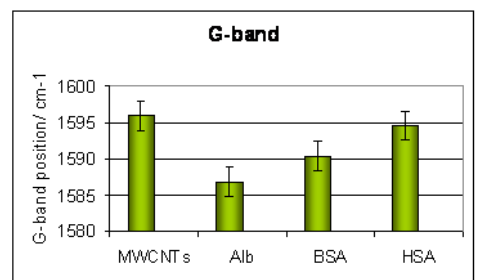

Fig. 4. Position of the G- band for the reference carbon layers (A) C-(CVD), and (B) MWCNTs (EPD), and after incubation with the selected proteins; $514.5 \mathrm{~nm}$ excitation line.

\subsection{D Raman Correlation Method}

Two-dimensional correlation uses mathematical formalism to obtain two-dimensional correlation spectra from any transient or time-resolved spectra of an arbitrary waveform [39, 40]. The experimental approach takes into account that an external perturbation, applied to a studied system, selectively excites various chemical constituents of the system. A 2D experiment in optical spectroscopy is performed by introducing a relatively slow external perturbation applied to the system of interest [41]. Spectral changes that are noticed under certain dynamic perturbation are the variation of intensities, shifts of spectral band positions, and alteration in the shape of peaks. These fluctuation of spectral signals are transformed into two-dimensional spectra by using a correlation method formalism. The type of physical information enclosed in a dynamic spectrum, is determined by the selection of perturbation method and electromagnetic probe. Therefore, 2D spectra obtained by 2D correlation method can highlight valuable information often hidden in the original time-resolved spectra.

\subsection{D Raman Correlation Spectroscopy Characterization of Carbon Layers Interaction with Selected Blood Proteins}

Carbon materials are characterized with a very high polarizability, therefore Raman spectroscopy is the method of choice for their analysis. However, the studied interaction occurs primarily in the interphase area, so not only carbon material, but also the complex biological structures of albumin are involved in the interaction. The most interesting would be to analyze the spectra in the vibration range of amide I, which is also the region of appearance of the D- and G-band of carbon layers. However, the Raman signal from the carbon component on the phase boundary might cover the spectrum of the protein, due to the high polarizability of $\mathrm{sp}^{2}$ system. Hence, a two-dimensional correlation analysis was used to control changes in the structure of the proteins on the interaction with the carbon layers in order to decode the relations hidden in the Raman spectra. [40, 42]. In the performed 2D correlation spectroscopy analysis the variable intensities were linked with a location on a sample characterizing the respective protein film carbon coating interactions. The 2D spectrum indicates the clear differentiation between the origins of the Raman spectral signals [40].

Synchronous signal fluctuations indicate a common chemical constituent at ca. 1588 and $1345 \mathrm{~cm}^{-1}$ and also at ca. 1613 and $1313 \mathrm{~cm}^{-1}$ originating from the graphite $\mathrm{G}$ and $\mathrm{D}$ - band components of the studied coating for the C (CVD) and MWCNTs layer, respectively.

The nonsynchronous signal fluctuations indicate chemically dissimilar components, thus the map pattern differs for the two carbon coatings and additionally animal albumins are clearly distinguishable from that of human (Figs. $5 \& 6$ ). The asynchronous correlation map for the C (CVD) + Alb layer in the 1720-1530 $\mathrm{cm}^{-1}$ range shows intensive negative cross-peaks originating from the amide I component bands at 1650 $\mathrm{cm}^{-1}$ ( $\alpha$-helix conf.), $1665 \mathrm{~cm}^{-1}$ ( $\beta$-sheet conf.) and $1682 \mathrm{~cm}^{-1}$ ( $\beta$-turn conf.) with the $1597 \mathrm{~cm}^{-1}$ band due to the G-band of the carbon layer. Otherwise it is for the C (CVD)+ BSA layer, there is an intensive positive band in a different location at $\left(1600,1552 \mathrm{~cm}^{-1}\right)$ that arises from the carbon G-band and Glu vibrations. The C (CVD)+ HSA layer presents a positive asynchronous peak derived of $1635 \mathrm{~cm}^{-1}$ (Trp, Arg, His) and 1652 $\mathrm{cm}^{-1}$ ( $\alpha$-helix conf.) and $1661 \mathrm{~cm}^{-1}$ ( $\beta$-sheet conf.) of amide I and at ca. $1594 \mathrm{~cm}^{-1}$ of the carbon layer G-band.

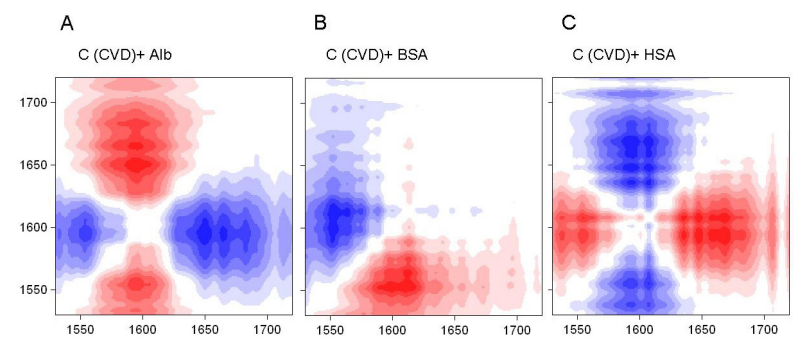

Fig. 5. Asynchronous 2D correlation Raman spectra of the $C(C V D)$ sample incubated with: (A) chicken egg white albumin (Alb); (B) bovine serum albumin (BSA); (C) human serum albumin (HSA); in the wavenumber range of $1720-1530 \mathrm{~cm}^{-1}$; the red and blue color represent positive and negative cross peaks, respectively.

A different pattern is observed for the 2D asynchronous maps for the second type carbon layer. The MWCNTs + Alb present a positive asynchronous correlation cross-peak at $1600 \mathrm{~cm}^{-1}$ of protein aromatic ring vibrations and $1622 \mathrm{~cm}^{-1}$ of Tyr with $1578 \mathrm{~cm}^{-1}$ of carbon nanotubes $\mathrm{G}^{-}$vibration. Another tested system MWCNTs +BSA shows intensive negative cross peak $-\left(1630,1602 \mathrm{~cm}^{-1}\right)$ owed to His, Tyr and $\left(\mathrm{G}^{+}\right)$carbon band and $-\left(1582,1603 \mathrm{~cm}^{-1}\right)$ originating from the $\mathrm{G}^{+}-$ band of the MWCNTs and the Phe albumin vibrations. 
Tab. 3. Observed significant asynchronous $2 D$ correlation cross-peaks and their assignments for the $C$ (CVD) and MWCNTs coating incubated in Alb, BSA, HSA in the wavenumber ranges of 1750-1500 cm-1 [20-28, 44-47].

\begin{tabular}{|c|c|c|c|c|c|}
\hline \multicolumn{6}{|c|}{ 2D asynchronous cross-peaks } \\
\hline \multicolumn{3}{|c|}{$\mathrm{C}(\mathrm{CVD})+\mathrm{Alb}$} & \multicolumn{3}{|c|}{ MWCNTs +Alb } \\
\hline assignment & cross-peaks & assignment & assignment & cross-peaks & assignment \\
\hline amide I, $\alpha$-helix conf. & $-(1650,1597)$ & G-band & Phe, His & $+(1600,1578)$ & $\mathrm{G}^{-}-$band \\
\hline amide I, $\beta$ - sheet conf. & $-(1665,1597)$ & G-band & Tyr & $+(1622,1578)$ & $\mathrm{G}^{-}$- band \\
\hline amide I, $\beta$-turn conf. & $-(1682,1597)$ & G-band & & & \\
\hline \multicolumn{3}{|c|}{$\mathrm{C}(\mathrm{CVD})+\mathrm{BSA}$} & \multicolumn{3}{|c|}{ MWCNTs +BSA } \\
\hline G-band & $+(1598,1552)$ & Glu & Phe & $+(1603,1583)$ & $\mathrm{G}^{+}$- band \\
\hline D'-band & $+(1613,1558)$ & Asp & His & $+(1630,1603)$ & $\mathrm{G}^{+}$- band \\
\hline \multicolumn{3}{|c|}{$\mathrm{C}(\mathrm{CVD})+\mathrm{HSA}$} & \multicolumn{3}{|c|}{ MWCNTs + HSA } \\
\hline D'-band & $+(1635,1601)$ & G-band & Tyr & $-(1618,1602)$ & $\mathrm{G}^{+}$- band \\
\hline D'-band & $+(1635,1594)$ & G-band & amide I, $\alpha$-helix conf. & $-(1660,1602)$ & $\mathrm{G}^{+}$- band \\
\hline amide I, $\alpha$-helix conf. & $+(1652,1601)$ & G-band & amide I, $\beta$-turn conf. & $-(1687,1601)$ & $\mathrm{G}^{+}$- band \\
\hline
\end{tabular}

The MWCNTs+ HSA layer gives a negative asynchronous peak - $(1618,1602)$ due to the Tyr and $\mathrm{G}^{+}$carbon band. The other cross-peak originated of the amide I band of $1659 \mathrm{~cm}^{-1}$ ( $\beta$-sheet conf.) and $1687 \mathrm{~cm}^{-1}$ ( $\beta$-turn conf.) with $1601 \mathrm{~cm}^{-1}\left(\mathrm{G}^{+}\right)$carbon nanotube vibrations.

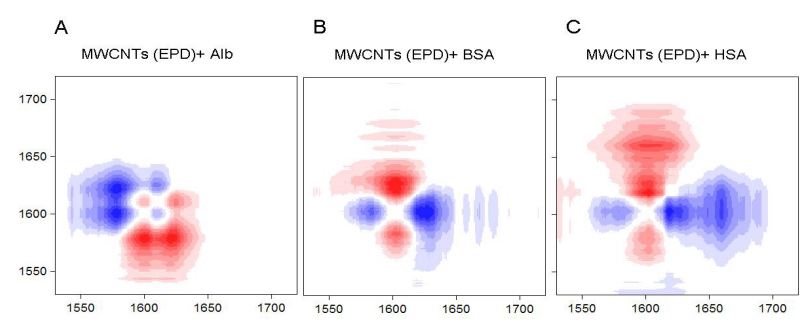

Fig. 6. Asynchronous 2D correlation Raman spectra of the MWCNTs (EPD) sample incubated with:

(A) chicken egg white albumin (Alb); (B) bovine serum albumin (BSA); (C) human serum albumin (HSA); in the wavenumber range of $1720-1530 \mathrm{~cm}^{-1}$. The red and blue color represent positive and negative cross peaks, respectively.

The calculated asynchronous cross-peaks are enclosed in Table 3. The 2D correlation spectroscopy allows to differentiate the adhesion specificity of the selected blood protein to the studied model, carbon layers.

\section{Summary}

The results of the performed complex studies of the two types of model carbon coatings display significant dissimilarities regarding their interaction with the chosen blood proteins but also the difference is related to the origin of a protein: whether it is animal or human. Both of the studied carbon layers were incubated with the selected albumins, and the interaction between these two materials is visible by the variation of the contact angle (Fig. 2). They substantially differ in their surface image, the nanotubes form an isotropic fibrous system with a characteristic nano topography while the C (CVD) pyrolytic surface is smoother (Fig. 2B).

For both types of the studied carbon layers a similar sequence of changes reflecting the occurring interaction with the albumins, which can be estimated by measuring contact angle. For each of the albumin, these differences are clearly marked, and a remarkably different contact angle is noticed for BSA (Fig. 2 $\mathrm{A}$ and $\mathrm{B}$ ). The CVD layer, which is known to be antithrombogenic, is characterized by high adhesion of protein to the surface while in other cases, the protein layer weakly adheres to the substrate (Table 1).

The results of Raman spectroscopy indicate that carbon layers interact differently with the selected blood proteins, as indicated by the parameters determined from the Raman spectra, e.g. the position of the characteristic G-bands (Fig. 3). This parameter allows to uncover the type of interactions and their extent.

The 2D asynchronous maps offer the possibility of determining the type of protein interaction with the surface of the carbon layer. Considering only the most intense cross-peaks you will notice that Alb adopts the structure with a comparable contribution of the $\alpha$-helix, $\beta$-sheet and a sizable portion of $\beta$-turn conformation while signals from the individual amino acids Phe, His, Tyr are observed for the MWCNTs layer (Fig. 5A \& 6A) [48-50]. For the BSA there is a correlation signal from the individual amino acids: Asp, Glu and Phe, His for C (CVD) and MWCNTs layer, respectively (Fig. 5B \& 6B ). [47-49]. The 2D correlation spectroscopy does not provide evidence that the secondary structure is mainly $\alpha$-helix (50-60\% in its native state) $[49,51,52]$. HSA acts in an exceptional way with a synthetic nanomaterial, showing equal participation conformation $\alpha$-helix and also $\alpha$-helix and 
b-turn in addition to the Tyr signal for the C (CVD) and MWCNTs layer, respectively [49,53]. But, the vibrations of the amide I are ahead of the changes in the carbon nanolayer for the C (CVD). The MWCNTs layer shows the opposite order of events (Fig. 5C \& 6C). The $2 \mathrm{D}$ analysis shows that the amide I bond is modified by the aromatic MWCNTs structure while the interaction on the interphase occurs, what was also noticed for the SWCNTs [54].

\section{Conclusion}

The albumin conformation is different for the studied surfaces, the amide I band maximum observed for the C (CVD) pyrolytic carbon layer shifts toward the higher vibrations for the MWCNT coating confirming an increase in the amide I of $\beta$-conformation. The conducted research and spectroscopic characteristics of the studied surfaces topography as a key element in the synthetic surface with blood protein interaction and allow for the explanation of the nature of this process in relation to the type of protein.

The phenomena occurring on the surface of the C-pyrolytic carbon with contact with human albumin have a different character than those observed in other cases. It can therefore be assumed that these phenomena, leading to the conformational changes in HSA and strong adhesion, indicates non-thrombogenic characteristic of this type surface coatings.

\section{ACKNOWLEDGEMENTS}

This project was financed from the National Science Centre (NCN, Poland) granted on the decision number DEC-2013/09/B/ST8/00146 and UMO-2014/13/B/ ST8/01195.

AK has been partly supported by the EU Project POWR.03.02.00-00-I004/16.

\section{AUTHORS}

Anna Kołodziej - Faculty of Chemistry, Jagiellonian University, Kraków, Poland.

Aleksandra Wesełucha-Birczyńska* - Faculty of Chemistry, Jagiellonian University, Kraków, Poland, email: birczyns@chemia.uj.edu.pl.

Paulina Moskal - Faculty of Chemistry, Jagiellonian University, Kraków, Poland.

Ewa Stodolak-Zych - Faculty of Materials Science and Ceramics, AGH-University of Science and Technology, Kraków, Poland.

Maria Dużyja - Technolutions, Łowicz, Poland.

Elżbieta Długoń - Faculty of Materials Science and Ceramics, AGH-University of Science and Technology, Kraków, Poland.

Julia Sacharz - Faculty of Chemistry, Jagiellonian University, Kraków, Poland.
Marta Błażewicz - Faculty of Materials Science and Ceramics, AGH-University of Science and Technology, Kraków, Poland.

*Corresponding author

\section{REFERENCES}

[1] L. Cademartiri and G. A. Ozin, Concepts of Nanochemistry, Wiley-VCH, 2009.

[2] S. K. Sahoo, S. Parveen, and J. J. Panda, "The present and future of nanotechnology in human health care", Nanomedicine: Nanotechnology, Biology and Medicine, vol. 3, no. 1, 2007, 20-31 10.1016/j.nano.2006.11.008.

[3] H. Lee and G. Kim, "Three-dimensional plotted PCL/ $\beta$-TCP scaffolds coated with a collagen layer: preparation, physical properties and in vitro evaluation for bone tissue regeneration", Journal of Materials Chemistry, vol. 21, no. 17, 2011, 6305-6312 10.1039/C0JM03414B.

[4] L. Zhang and T. J. Webster, "Nanotechnology and nanomaterials: Promises for improved tissue regeneration", Nano Today, vol. 4, no. 1 , 2009, 66-80 10.1016/j.nantod.2008.10.014.

[5] D.-E. Lee, H. Koo, I.-C. Sun, J. H. Ryu, K. Kim, and I. C. Kwon, "Multifunctional nanoparticles for multimodal imaging and theragnosis", Chemical Society Reviews, vol. 41, no. 7, 2012, 2656-2672 10.1039/C2CS15261D.

[6] E. L. da Rocha, L. M. Porto, and C. R. Rambo, "Nanotechnology meets 3D in vitro models: Tissue engineered tumors and cancer therapies", $M a-$ terials Science and Engineering: C, vol. 34, 2014, 270-279 10.1016/j.msec.2013.09.019.

[7] A. Chen and S. Chatterjee, "Nanomaterials based electrochemical sensors for biomedical applications", Chemical Society Reviews, vol. 42, no. 12, 2013, 5425-5438 10.1039/C3CS35518G.

[8] T. K. Dash and V. B. Konkimalla, "Poly$\epsilon$-caprolactone based formulations for drug delivery and tissue engineering: A review", Journal of Controlled Release, vol. 158, no. 1, 2012, 15-33 10.1016/j.jconrel.2011.09.064.

[9] R. Parikh and S. Dalwadi, "Preparation and characterization of controlled release poly$\varepsilon$-caprolactone microparticles of isoniazid for drug delivery through pulmonary route", Powder Technology, vol. 264, 2014, 158-165 10.1016/j.powtec.2014.04.077. 
[10] Y. Shen, ed., Functional Polymers for Nanomedicine, RSC Publishing: Cambridge, UK, 2013.

[11] L. Chen, D. Han, and L. Jiang, “On improving blood compatibility: From bioinspired to synthetic design and fabrication of biointerfacial topography at micro/nano scales", Colloids and Surfaces B: Biointerfaces, vol. 85, no. 1, 2011, 2-7 DOI: $10.1016 /$ j.colsurfb.2010.10.034.

[12] R.O. Ritchie, "Fatigue and fracture of pyrolytic carbon: a damage-tolerant approach to structural integrity and life prediction in "ceramic" heart valve prostheses", Journal of Heart Valve Disease, vol. 5, Suppl. 1, 1996, 9-31.

[13] H. Cao, "Mechanical performance of pyrolytic carbon in prosthetic heart valve applications", Journal of Heart Valve Disease, vol. 5, Suppl. 1, 1996, 32-49.

[14] M. S. Scholz, J. P. Blanchfield, L. D. Bloom, B. H. Coburn, M. Elkington, J. D. Fuller, M. E. Gilbert, S. A. Muflahi, M. F. Pernice, S. I. Rae, J. A. Trevarthen, S. C. White, P. M. Weaver, and I. P. Bond, "The use of composite materials in modern orthopaedic medicine and prosthetic devices: A review", Composites Science and Technology, vol. 71, no. 16, 2011, 1791-1803 DOI: 10.1016/j.compscitech.2011.08.017.

[15] Y. Hanein and L. Bareket-Keren, "Carbon nanotube-based multi electrode arrays for neuronal interfacing: progress and prospects", Frontiers in Neural Circuits, vol. 6, 2013 DOI: $10.3389 /$ fncir.2012.00122.

[16] J.-Y. Hwang, U. S. Shin, W.-C. Jang, J. K. Hyun, I. B. Wall, and H.-W. Kim, "Biofunctionalized carbon nanotubes in neural regeneration: a mini-review", Nanoscale, vol. 5, no. 2, 2012, 487-497 DOI: 10.1039/C2NR31581E.

[17] G. A. Silva, "Neuroscience nanotechnology: progress, opportunities and challenges", Nature Reviews Neuroscience, vol. 7, no. 1, 2006, 65-74 DOI: $10.1038 / \mathrm{nrn} 1827$.

[18] V. C. Sanchez, A. Jachak, R. H. Hurt, and A. B. Kane, "Biological Interactions of Graphene-Family Nanomaterials: An Interdisciplinary Review", Chemical Research in Toxicology, vol. 25, no. 1, 2012, 15-34 DOI: $10.1021 /$ tx200339h.

[19] E. Engel, A. Michiardi, M. Navarro, D. Lacroix, and J. A. Planell, "Nanotechnology in regenerative medicine: the materials side", Trends in Biotechnology, vol. 26, no. 1, 2008, 39-47 DOI: 10.1016/j.tibtech.2007.10.005.

[20] A. Wesełucha-Birczyńska, A. Frączek-Szczypta, E. Długoń, K. Paciorek, A. Bajowska, A. Kościelna, and M. Błażewicz, "Application of Raman spec- troscopy to study of the polymer foams modified in the volume and on the surface by carbon nanotubes", Vibrational Spectroscopy, vol. 72, 2014, 50-56

DOI: 10.1016/j.vibspec.2014.02.009.

[21] A. Wesełucha-Birczyńska, M. Swiętek, E. Sołtysiak, P. Galiński, Ł. Płachta, K. Piekara, and M. Błażewicz, "Raman spectroscopy and the material study of nanocomposite membranes from poly( $\varepsilon$-caprolactone) with biocompatibility testing in osteoblast-like cells", Analyst, vol. 140, no. $7,2015,2311-2320$ DOI: $10.1039 / C 4 A N 02284 J$.

[22] F. Poncin-Epaillard, T. Vrlinic, D. Debarnot, M. Mozetic, A. Coudreuse, G. Legeay, B. El Moualij, and W. Zorzi, "Surface Treatment of Polymeric Materials Controlling the Adhesion of Biomolecules", Journal of Functional Biomaterials, vol. 3 , no. $3,2012,528-543$ DOI: $10.3390 / \mathrm{jfb} 3030528$.

[23] A. Frączek-Szczypta, E. Długoń, A. Wesełucha-Birczyńska, M. Nocuń, and M. Błażewicz, "Multi walled carbon nanotubes deposited on metal substrate using EPD technique: A spectroscopic study", Journal of Molecular Structure, vol. 1040, 2013, 238-245

DOI: 10.1016/j.molstruc.2013.03.010.

[24] Benko, A. Przekora, A. Wesełucha-Birczyńska, M. Nocuń, G. Ginalska, and M. Błażewicz, "Fabrication of multi-walled carbon nanotube layers with selected properties via electrophoretic deposition: physicochemical and biological characterization", Applied Physics A, vol. 122, no. 4, 2016

DOI: $10.1007 / s 00339-016-9984-z$.

[25] Wesełucha-Birczyńska, E. Stodolak-Zych, S. Turrell, F. Cios, M. Krzuś, E. Długoń, A. Benko, W. Niemiec, and M. Błażewicz, "Vibrational spectroscopic analysis of a metal/carbon nanotube coating interface and the effect of its interaction with albumin", Vibrational Spectroscopy, vol. 85, 2016, 185-195

DOI: 10.1016/j.vibspec.2016.04.008.

[26] Wesełucha-Birczyńska, E. Stodolak-Zych, W. Piś, E. Długoń, A. Benko, and M. Błażewicz, "A model of adsorption of albumin on the implant surface titanium and titanium modified carbon coatings (MWCNT-EPD): 2D correlation analysis", Journal of Molecular Structure, vol. 1124, 2016, 61-70 DOI: 10.1016/j.molstruc.2016.04.050.

[27] R. Vajtai, ed., Springer Handbook of Nanomaterials, Springer Handbooks, Springer-Verlag: Berlin Heidelberg, 2013 DOI: 10.1007/978-3-642-20595-8. 
[28] A. C. Ferrari and J. Robertson, "Interpretation of Raman spectra of disordered and amorphous carbon", Physical Review B, vol. 61, no. 20, 2000, 14095-14107 DOI: 10.1103/PhysRevB.61.14095.

[29] S. Iijima, "Helical microtubules of graphitic carbon", Nature, vol. 354, 1991, 56-58 DOI: $10.1038 / 354056 a 0$.

[30] L. E. Murr and P. A. Guerrero, "Carbon nanotubes in wood soot", Atmospheric Science Letters, vol. 7, no. 4, 2006, 93-95

DOI: $10.1002 /$ asl.138.

[31] J. J. Bang, P. A. Guerrero, D. A. Lopez, L. E. Murr, and E. V. Esquivel. "Carbon Nanotubes and Other Fullerene Nanocrystals in Domestic Propane and Natural Gas Combustion Streams", Journal of Nanoscience and Nanotechnology, vol. 4, no. 7, 2004, 716-718 DOI: 10.1166/jnn.2004.095.

[32] N. Sinha and J.-W. Yeow, "Carbon nanotubes for biomedical applications", IEEE Transactions on NanoBioscience, vol. 4, no. 2, 2005, 180-195 DOI: $10.1109 /$ TNB.2005.850478.

[33] S. Zhang, Biological and Biomedical Coatings Handbook: Applications, CRC Press, 2017.

[34] S. Park and K. Hamad-Schifferli, "Nanoscale interfaces to biology", Current Opinion in Chemical Biology, vol. 14, no. 5, 2010, 616-622 DOI: $10.1016 /$ j.cbpa.2010.06.186.

[35] H. Cui and P. J. Sinko, "The role of crystallinity on differential attachment/proliferation of osteoblasts and fibroblasts on poly (caprolactone-co-glycolide) polymeric surfaces", Frontiers of Materials Science, vol. 6, no. 1, 2012, 47-59 DOI: $10.1007 / \mathrm{s} 11706-012-0154-8$.

[36] N. R. Washburn, K. M. Yamada, C. G. Simon, S. B. Kennedy, and E. J. Amis, "High-throughput investigation of osteoblast response to polymer crystallinity: influence of nanometerscale roughness on proliferation", Biomaterials, vol. 25, no. $7,2004,1215-1224$ DOI: 10.1016/j.biomaterials.2003.08.043.

[37] K. Anselme, "Osteoblast adhesion on biomaterials", Biomaterials, vol. 21, no. 7, 2000, 667-681 DOI: 10.1016/S0142-9612(99)00242-2.

[38] J. Schaller, S. Gerber, U. Kämfer, S. Lejon, and C. Trachsel, Human Blood Plasma Proteins, John Wiley \& Sons, Ltd: Chichester, UK, 2008 DOI: $10.1002 / 9780470724378$.

[39] I. Noda and Y. Ozaki, Two-dimensional Correlation Spectroscopy: Aplications in Vibrational and Optical Spectroscopy, John Wiley \& Sons, 2004.

[40] I. Noda, A. E. Dowrey, C. Marcott, G. M. Story, and Y. Ozaki, "Generalized Two-Dimensional Cor- relation Spectroscopy", Applied Spectroscopy, vol. 54, no. 7, 2000, 236A-248A DOI: $10.1366 / 0003702001950454$.

[41] I. Noda, "Generalized Two-Dimensional Correlation Method Applicable to Infrared, Raman, and Other Types of Spectroscopy", Applied Spectroscopy, vol. 47, no. 9, 1993, 1329-1336 DOI: $10.1366 / 0003702934067694$.

[42] H. Shinzawa, K. Awa, and Y. Ozaki, "Compression-Induced Morphological and Molecular Structural Changes of Cellulose Tablets Probed with near Infrared Imaging", Journal of Near Infrared Spectroscopy, vol. 19, no. 1, 2011, 15-22 DOI: $10.1255 /$ jnirs.918.

[43] "Shigeaki Morita - 2DShige software". https:// sites.google.com/view/shigemorita/home/2dshige. Accessed on: 2019-11-08.

[44] A. C. Ferrari, J. Robertson, "Raman spectroscopy of amorphous, nanostructured, diamond-like carbon, and nanodiamond", Philosophical Transactions of the Royal Society of London. Series A, vol. 362, no. 1824, 2004, 2477-2512 DOI: $10.1098 /$ rsta.2004.1452.

[45] M. S. Dresselhaus, G. Dresselhaus, J. C. Charlier, and E. Hernández, "Electronic, thermal and mechanical properties of carbon nanotubes", Philosophical Transactions of the Royal Society of London. Series A, vol. 362, no. 1823, 2004, 2065-2098 DOI: $10.1098 /$ rsta.2004.1430.

[46] H. Lehman, M. Terrones, E. Mansfield, K. E. Hurst, and V. Meunier, "Evaluating the characteristics of multiwall carbon nanotubes", Carbon, vol. 49, no. 8, 2011, 2581-2602

DOI: 10.1016/j.carbon.2011.03.028.

[47] A. Wesełucha-Birczyńska, K. Babeł, and K. Jurewicz, "Carbonaceous materials for hydrogen storage investigated by 2D Raman correlation spectroscopy", Vibrational Spectroscopy, vol. 60, 2012, 206-211] DOI: 10.1016/j.vibspec.2012.01.008.

[48] C. Lewis, N. S. Snell, D. J. Hirschmann, and H. Fraenkel-Conrat, "Amino acid composition of egg proteins", The Journal of Biological Chemistry, vol. 186, no. 1, 1950, 23-35.

[49] A. T. Tu, Raman spectroscopy in biology: Principles and applications, Wiley: New York, 1982.

[50] A. Synytsya, M. Judexová, T. Hrubý, M. Tatarkovič, M. Miškovičová, L. Petruželka, and V. Setnička, "Analysis of human blood plasma and hen egg white by chiroptical spectroscopic methods (ECD, VCD, ROA)", Analytical and Bioanalytical Chemistry, vol. 405, no. 16, 2013, 5441-5453 DOI: $10.1007 / s 00216-013-6946-6$. 
[51] G. Anderle and R. Mendelsohn, "Thermal denaturation of globular proteins. Fourier transforminfrared studies of the amide III spectral region", Biophysical Journal, vol. 52, no. 1, 1987, 69-74 DOI: 10.1016/S0006-3495(87)83189-2.

[52] L. Lippert, D. Tyminski, and P. J. Desmeules, “Determination of the secondary structure of proteins by laser Raman spectroscopy", Journal of the American Chemical Society, vol. 98, no. 22, 1976, 7075-7080

DOI: $10.1021 / \mathrm{ja} 00438 \mathrm{a} 057$.

[53] B. Meloun, L. Morávek, and V. Kostka, "Complete amino acid sequence of human serum albumin", FEBS Letters, vol. 58, no. 1-2, 1975, 134-137 DOI: $10.1016 / 0014-5793(75) 80242-0$.

[54] Zhong, L. Song, J. Meng, B. Gao, W. Chu, H. Xu, Y. Luo, J. Guo, A. Marcelli, S. Xie, and Z. Wu, "Bio-nano interaction of proteins adsorbed on single-walled carbon nanotubes", Carbon, vol. 47, no. 4, 2009, 967-973

DOI: 10.1016/j.carbon.2008.11.051. 